\title{
A preliminary study on causatives in Italian Sign Language
}

\author{
Mirko Santoro (SFL, CNRS, Université Paris 8), \\ mirko.santoro@cnrs.fr \\ Valentina Aristodemo (Dipartimento di Psicologia e Scienze Cognitive, \\ Università di Trento \& Laboratoire CLLE, CNRS, \\ Université Toulouse II Jean Jaurès) \\ vale.aristodemo@gmail.com
}

\begin{abstract}
Causal constructions are structures in which the verbs refer to a causative situation between two events. Typologically, these structures can be distinguished in three groups: lexical, morphological and syntactic causatives. This work presents preliminary data showing that Italian Sign Language (LIS) displays all the typological categories of causatives. Additionally, we show that syntactic causatives in LIS can be mono-clausal or bi-clausal and we propose a formal analysis for them. Finally, we show that causative structures in LIS can also be expressed using an independent non-manual component. This strategy is an instance of syntactic causation.
\end{abstract}

Keywords: Causatives, Italian Sign Language, morphology, syntax.

\section{Introduction}

Causatives are constructions that typically involve a causing event (causer) and a caused event (causee). Specifically, Kulikov $(2001,886)$ defines causatives as '...verbs that refer to a causative situation, that is, a causal relationship between two events, one of which (P2) is believed by the speaker to be caused by another (P1). In other words, a causative is a verb or verbal construction that means 'to cause VO', 'to make VO', where VO stands for the embedded base verb.'

Causative verbs have been well studied in the literature in both spoken and signed languages, however so far no work has been done on this topic in Italian Sign Language (LIS). This work investigates causative constructions in LIS. We show that the three typological categories of causatives attested in other languages (i.e. lexical, morphological and syntactic causatives) are also found in LIS. Additionally, we provide a formal analysis of LIS syntactic causatives.

The paper is organized as follows: Section 2 presents the typology of causatives providing examples from both spoken and sign languages. Section 3 describes causatives in LIS. Section 4 provides a formal analysis of LIS syntactic causatives. Section 5 concludes the paper.

\section{Notational conventions}

Following standard conventions in sign language linguistics, glosses are given using small 
caps. Pronouns are indicated using the gloss IX followed by a subscript number for first, second or third person. Reduplication of a sign is indicated by using the + symbol. Fingerspelled forms are set in small-caps, separated by hyphens. Finally, a line above the glosses signals the presence of non-manual marking and its scope. The label above that line describes its grammatical function. The absence of a manual sign during the articulation of a specific non-manual marking is indicated using the symbol $\varnothing$ in the glossing line. In the examples cited from other sources, the original glossing conventions are followed.

\section{Typology of causatives}

Causatives can be distinguished depending on how the meaning of cause is expressed. Kulikov (2001) distinguishes three formal categories of causative structures: lexical, morphological and syntactic causatives. Recent works (Benedicto and Brentari 2004; Kimmelman 2018; Loos et al. 2017; Gutman 2010; Tang and Yang 2007; Kayabaşı and Gökgöz 2020, among others) have shown that these categories are also attested in sign languages, including American Sign Language (ASL), Russian Sign Language (RSL), German Sign Language (DGS), French Sign Language (LSF), among others.

Lexical causatives are those in which causation is expressed by the verb itself. This is the case of the verb kill in English. Example (1), indeed, means 'John caused Henry to be dead'.

\section{(1) John killed Henry.}

A special subtype of lexical causatives is called labile verbs. These verbs are formally indistinguishable from their non-causative counterparts, called inchoatives. While labile verbs are transitive, their non-causative (i.e. inchoative) couterparts are intransitive, as shown in (2) and (3).

(2) Labile form:

John opened the door.

(3) Inchoative form:

The door opened.

Lexical causatives are also attested in sign languages, as described by Gutman (2010) for LSF (cf. (4)).

(4) TIGRE TUER ELEPHANT

tiger kill elephant

'The tiger killed the elephant.' (LSF, Gutman 2010)

As for labile verbs in sign languages, we report an example from RSL in (5). The labile verb BOIL in (5) is used transitively given that 'father' is the subject and 'rice' is the object.

(5) FATHER R-I-S BOIL1 DONE

'The father boiled/cooked the rice.' (RSL, Kimmelman 2018, 13)

The inchoative form of the verb BOIL is shown in (6).

(6) WATER BOIL1

'The water boiled.' (RSL, ibid.) 
In morphological causatives, causation is expressed by a causative morpheme which is an affix and applies to the base (non-causative) verb. Morphological causatives are exemplified by the sentence in (7) in which the causative morpheme tua is attached to the non-causative verb hitto (i.e. treat).
Maria [hitevi-ta
uusi-ta hitto]-tua-k
Maria [doctor-ACC child-ACC treat]-CAUSE-PERF

'Maria made the doctor treat the child.' (Hiaki, Tubino Blanco 2010, 255)

Moving to the sign language literature, Benedicto and Brentari (2004) argue that morphological causation is expressed by the handshape of the handling classifier morpheme, glossed as HDCL. Differently, Tang and Yang (2007) argue that causation is expressed by the morpheme that corresponds to the movement of the handling classifier element. We show in (8) an example from ASL.

(8) INDEX BOOK C+MOVE S/HE BOOK OBJ GRAB HDCL-MOVE-VERTICAL-TO-HORIZONTAL 'S/he took the (standing) book and laid it down on its side.' (ASL, Benedicto and Brentari 2004, 769)

Finally, we move to syntactic causatives, also called periphrastic causatives. These are those in which causation is expressed by a causative morpheme which is a free form, typically a verb meaning 'cause', 'make', 'let', 'give', etc. We show in (9) an example from French.

(9) Je ferai courir Henriette

'I shall make Henriette run.' (French, Comrie 1976, 262)

Syntactic causative in sign language is exemplified by the LSF sentence in (10) in which the element expressing causation is the verb DONNER.

(10) AMI MOI DONNER-MOI RIRE

Friend I 3.give-1 laugh

'My friend made me laugh.' (LSF, Gutman 2010)

\section{Causatives in LIS}

In this section we present our LIS data on causatives. Specifically, we show that all the typological categories presented in the previous section are attested in LIS. However, in some cases, some restrictions can be at work.

Lexical causation is LIS is shown in the example in (11) containing the causative verb UCCIDERE (i.e. 'kill') which is illustrated in Figure 1.

(11) IX 1 MARIA UCCIDERE

I Maria kill

'I killed Maria.' 
Figure 1: The sign UCCIDERE ('kill')
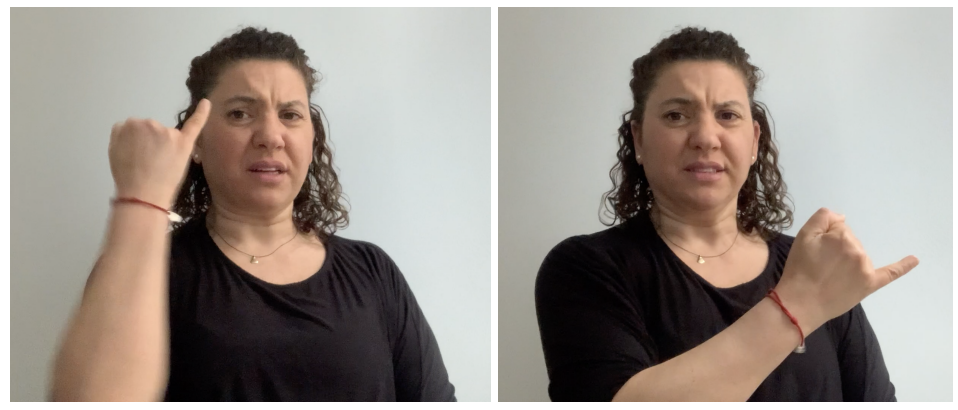

The example in (12) shows a sentence containing the labile verb APRIRE (i.e. 'open'), while the sentence in (13) contains the inchoative counterpart of the same verb. Labile and the inchoative forms have the same phonological properties (see Figure 2).

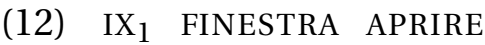

I windows open

'I opened the windows.'

(13) FINESTRA APRIRE

windows open

'the windows is open.'

Figure 2: The sign APRIRE ('open')
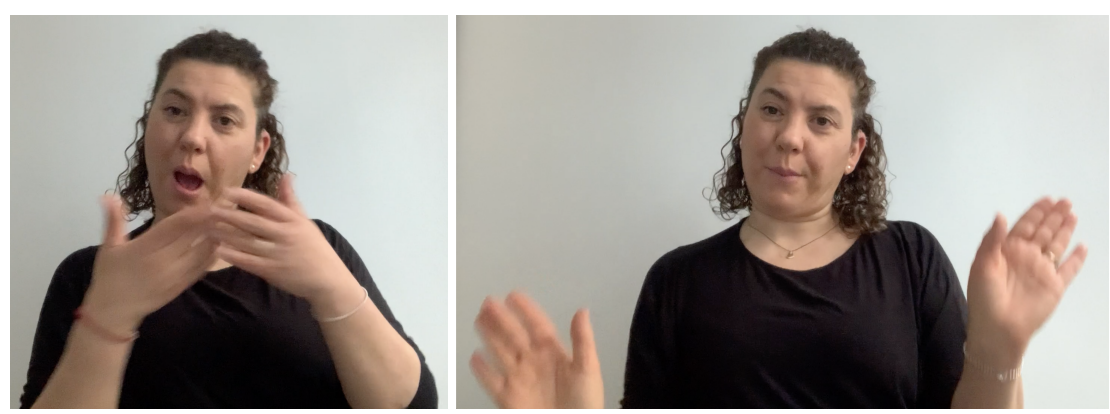

Morphological causatives in LIS are exemplified by the sentence in (14). Here, the handling classifier (HDCL) is the element that introduces the morpheme responsible for the causative interpretation.

(14) Pietro LIBRo HDCL-MOVE-VERTICAL-TO-HORIZONTAL

Pietro book grab-lay-down-on-its-side

'Pietro took the (standing) book and laid it down on its side.'

In LIS, we found several syntactic causative forms. The first strategy used to express syntactic causatives is by means of the agreeing verbs DARE- 1 and DARE-2. Both these verbs means 'give' and are articulated in the signing space, however they are produced with a different handshape, as shown in Figure 3 and Figure 4. 
Figure 3: The syntactic causative form DARE-1 ('give')

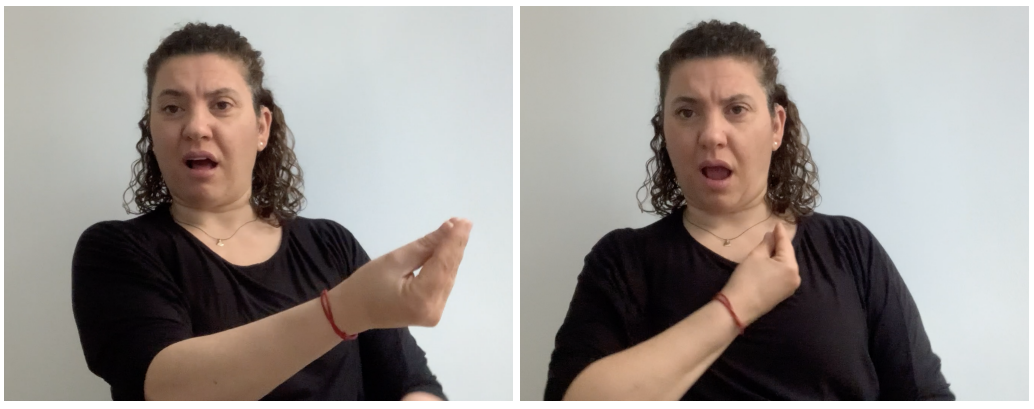

Figure 4: The syntactic causative form DARE-2 ('give')
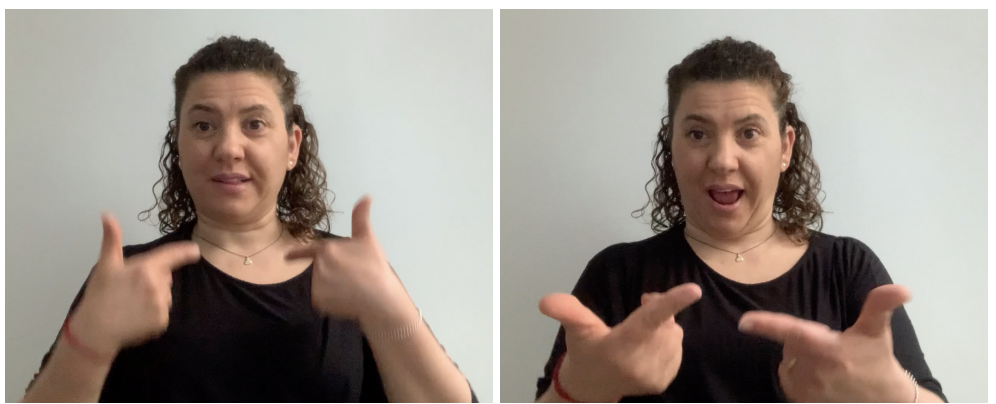

Interestingly, these forms are not used interchangeably. DARE-1 can be used in positive environment only, while DARE-2 is accepted in both positive and negative environments. The contrast in (15) and (16) shows that while it is possible to use DARE-1 with a positive adjective, as calm, this is not acceptable using negative properties, like nervous.

(15) TISANA DARE-1 CALM

herbal.tea give calm

'Herbal tea makes me calm.'

(16) \# CAFFÈ DARE-1 NERVOSO

Coffee give nervous

Intended: 'Coffee makes me nervous.'

These restrictions are not at work when DARE-2 is used, as shown in (17) and (18).

(17) TISANA DARE-2 CALM

herbal.tea give calm

'Herbal tea makes me calm.'

(18) CAFFÈ DARE-2 NERVOSO

Coffee give nervous

'Coffee makes me nervous.'

The second strategy to express syntactic causatives is shown by the sentence in (19). The causative element, COSTRINGERE (i.e., 'force'), is presented in Figure 5. 
(19)
MARIA PIETRO STUDIARE COSTRINGERE

'Maria Pietro study force.'

'Maria forced Pietro to study.'

Figure 5: The syntactic causative verb COSTRINGERE ('force')
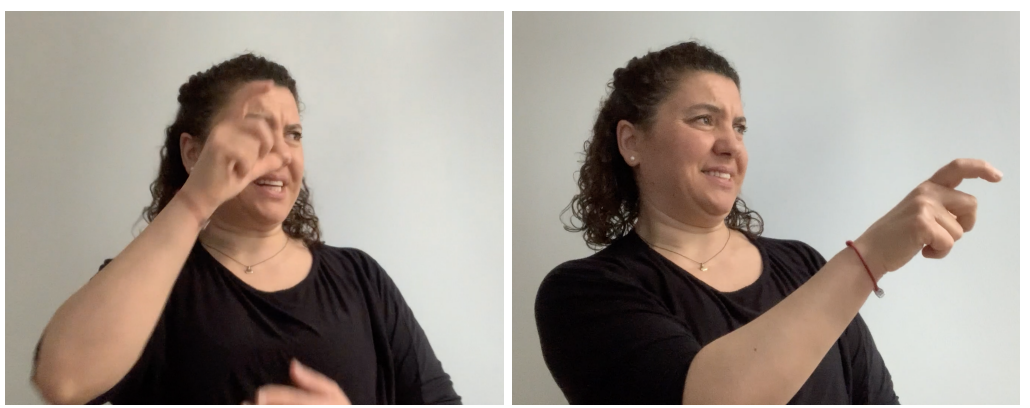

Another strategy to produce a causative sentence is by using the verb DIVENTARE (i.e.become), shown in Figure 6, which, in such examples, does not have its literal meaning but it is used to trigger a causative interpretation. The sentence in (20) exemplifies this strategy.

Figure 6: The syntactic causative verb DIVENTARE ('become')
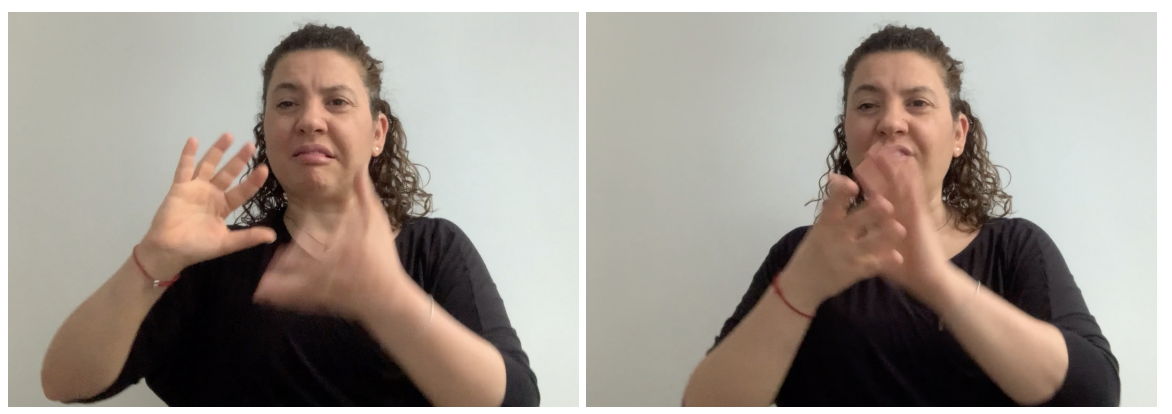

(20)
POLITICA LITIGARE+++ DIVENTARE PERSONE VOTO RINUNCIARE
Politics fight.PL become people vote give.up
'The constant fighting of politicians makes people give up voting.'

Finally, causation in LIS can be also expressed by using a non-manual marking expression ( $h n$-cause), which is obligatory when the manual sign is not present. The hn-cause marking involves several features including head nod, squint eyes and furrowed eyebrows (see Figure 7). The relevant example is illustrated in (21). 
Figure 7: Non-manual marking used to express causation in LIS
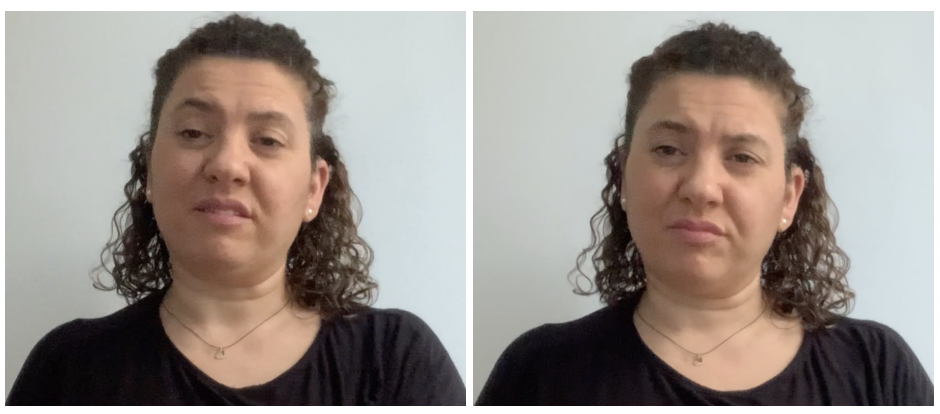

(21)

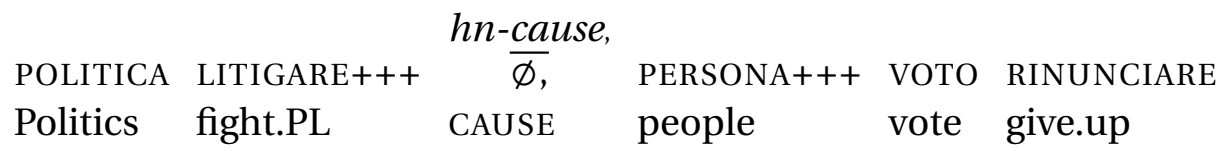

'The constant fighting of politicians makes people give-up voting.'

The non-manual element, indicated as $h n$-cause, is a morphological independent element articulated between the clause expressing the causer and the one expressing the causee. Interestingly, the non-manual element is also in complementary distribution with the causative sign DIVENTARE, as displayed by the sentences in (20) and (21).

\section{Syntactic causatives: a possible analysis}

In the previous section, we showed that the typological categories of causatives attested in spoken languages and other sign languages are also found in LIS. Additionally, we found that causatives in LIS can be also expressed by using a non-manual marking component which is articulated as an independent element.

In this section we provide a preliminary analysis for the syntactic causative sentences shown in Section 3. In particular, we argue that syntactic causatives containing the verb DARE-1, DARE-2 and COSTRINGERE are mono-clausal, while those expressed using the verb DIVENTARE are bi-clausal.

Our claim that sentences with DARE-1, DARE-2 and COSTRINGERE are mono-clausal is supported by the fact that these verbs behave like light verbs. Indeed, if we introduce a temporal adverb it always has wide scope, as shown in (22). The adverb IERI ('yesterday') can be inserted in different position of the sentence without changing its meaning.

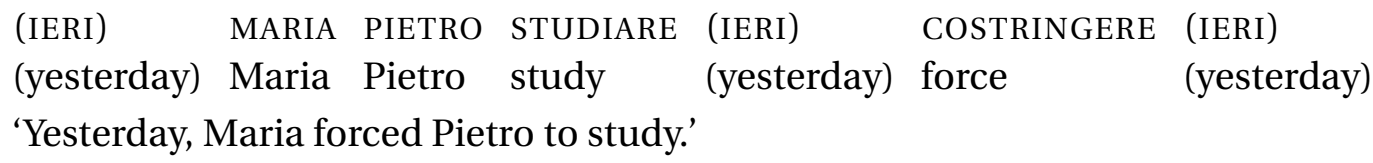

Moreover, it is not possible to insert another temporal adverb (e.g. OGGI, 'today') targeting the verb 'to study', as shown by the ungrammatical sentences in (23) and (24).

* IERI MARIA PIETRO STUDIARE OGGI COSTRINGERE
yesterday Maria Pietro study today force
'Yesterday, Maria forced Pietro to study today.'




$$
\begin{aligned}
& \text { * ieri maria pietro studiare costringere ogGi } \\
& \text { yesterday Maria Pietro study force today }
\end{aligned}
$$

'Yesterday, Maria forced Pietro to study today.'

All these properties suggest that we are dealing with a periphrastic mono-clausal structure.

Now we move to sentences containing the verb DIVENTARE. In these sentences, it is possible to insert two temporal adverbs, as in (25). As you can see, each adverb modifies one of the clauses.

(25) PASSATO POLITICA LitigARE+++ DIVENTARE OGgI PERSONE VOTO RINUNCIARE Past politics fight-PL become today people vote give-up 'The constant fighting of politicians in the past made, nowadays, people give up voting.'

There are several analyses in the literature that account for causative structures (see Harley 1995; Folli and Harley 2007; Harley 2008; Pylkkänen 2002, 2008; Tubino Blanco 2010; Martin and Schäfer 2014, among others). For our analysis we follow Pylkkänen (2008) and Tubino Blanco (2010) which propose that causer arguments are introduced by Voice, as shown in Figure 8.

Figure 8: Structure of syntactic causatives proposed by Tubino Blanco $(2010,198)$

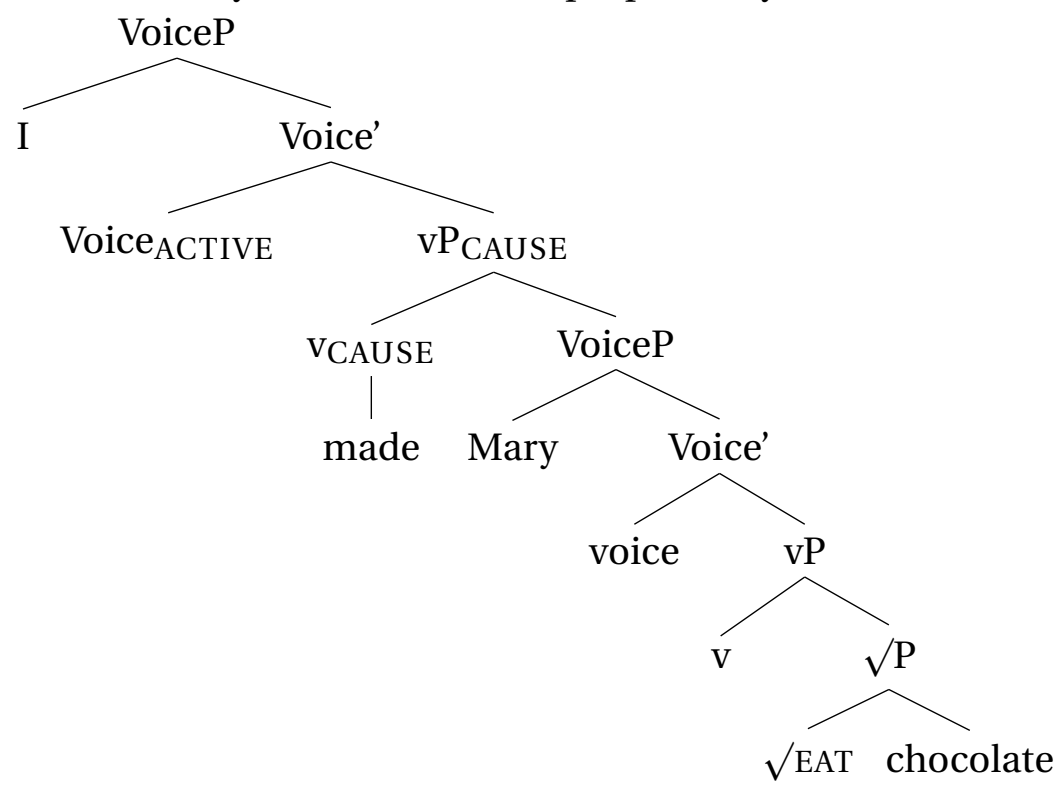

As for LIS, we propose that mono-clausal causative sentences have the structure represented in Figure 9. The sign COSTRINGERE (i.e.'force'), which is the element expressing causation, is generated as head on the vPCAUSE projection. To better understand the structure, we would like to remind you that LIS is a head-final SOV language (for details see Cecchetto, Geraci, and Zucchi 2006 and Cecchetto, Geraci, and Zucchi 2009). 
Figure 9: Structure of mono-clausal syntactic causative in LIS

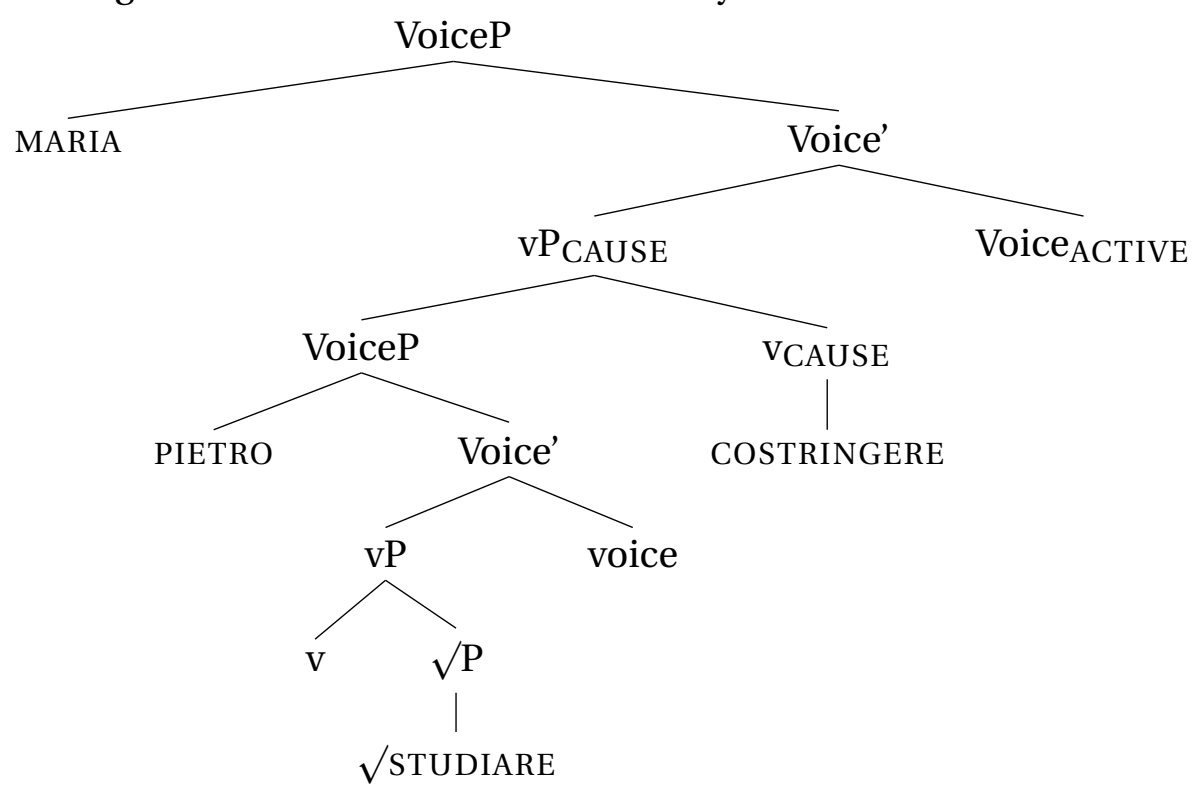

The structure of LIS bi-clausal causative sentences is represented in Figure 10. Here, the $\mathrm{V}_{\text {CAUSE }}$ head contains the causative element DIVEnTARE ('become'). As the reader may notice, the object $\left(\mathrm{XP}_{1}\right.$ moves from its original place to right edge). This movement happens because heavy objects in LIS need to be moved from their original positions to either a right or a left position of the sentence, as argued by Geraci, Cecchetto, and Zucchi (2008) and Geraci and Aristodemo (2016).

Figure 10: Structure of bi-clausal syntactic causative in LIS

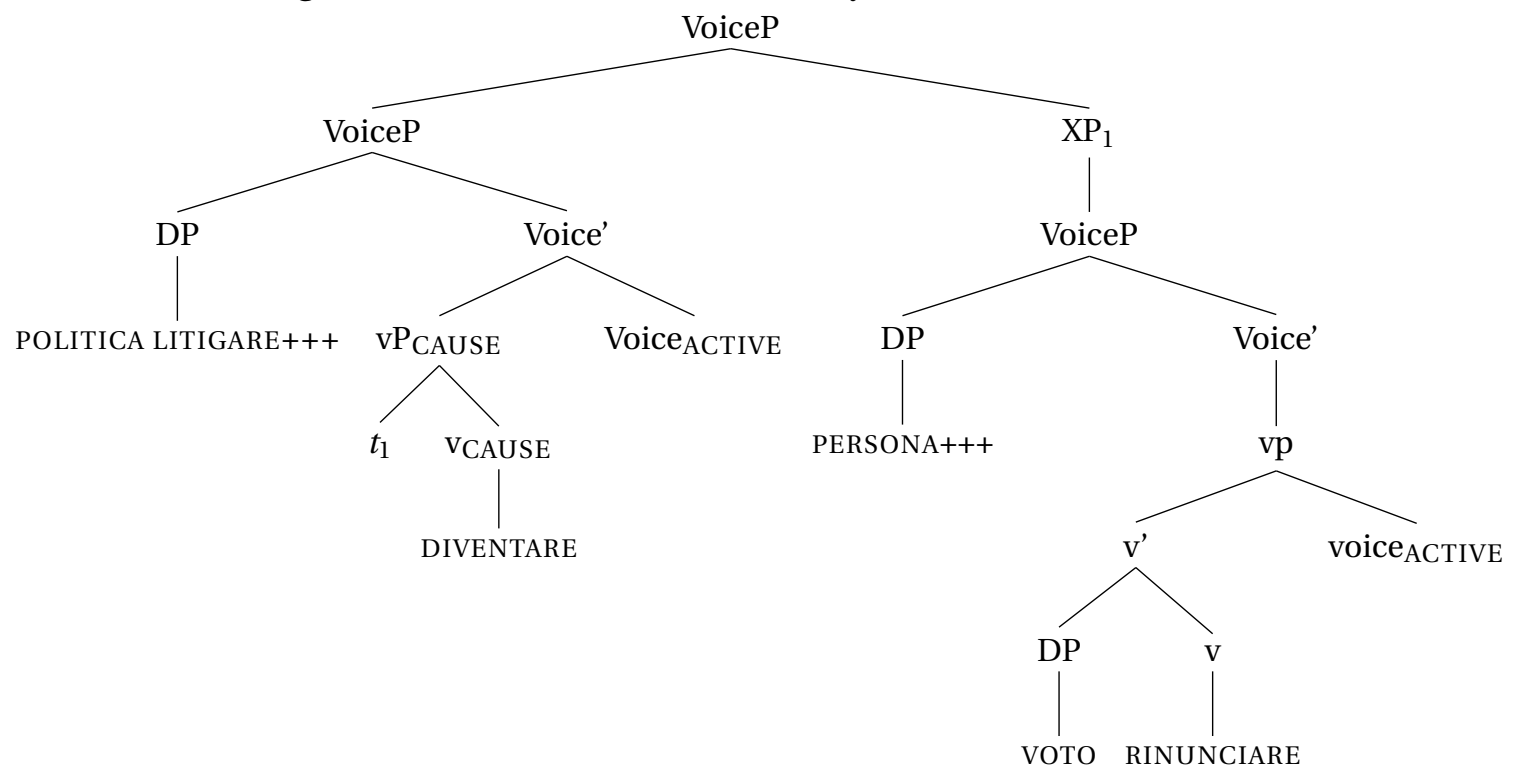

Finally, as for the sentences containing the causal non-manual marking element (cf.(21)), we propose that these are instances of syntactic causation composed by two clauses. Two pieces of evidence support our claim: i) the non-manual marking element is morphologically independent and ii) it can be replaced by the syntactic causative verb DIVENTARE. Both these properties suggest that we can apply the bi-clausal analysis in Figure 10 to sentences 
containing the non-manual element expressing causation. In this case, the non-manual component is generated in $\mathrm{V}_{\mathrm{CAUSE}}$.

\section{Conclusion}

Our study investigates for the first time causative structures in LIS. In this paper, we have presented some preliminary data showing that the typological categories of causatives (lexical, morphological and syntactic) attested in other languages are also found in LIS. Focusing on syntactic causatives, we have shown that these structures can be expressed by using several verbs in LIS, such as DARE-1, DARE-2, COSTRINGERE and DIVENTARE, and also a specific independent non-manual component with a causal meaning. Additionally, we have argued that while syntactic causatives containing the verbs DARE-1, DARE- 2 and FORCE are monoclausal, those containing the verb DIVENTARE and the independent $h n$-cause element are bi-clausal. Finally, we provided a formal analysis for them.

Clearly, given that our research is only at a preliminary stage, further research is is necessary to have a more exhaustive picture of LIS causatives. For the future, we plan to conduct a deeper investigation which will possibly include a semantic analysis of these structures.

\section{Acknowledgments}

We wish to thank the Italian Deaf community and in particular our LIS consultants. This work would not be possible without them. The work also benefited from discussion with Carlo Geraci and Fabio Del Prete, as well as the audience at FEAST 2021.

\section{References}

Benedicto, Elena, and Diane Brentari. 2004. "Where did all the arguments go?: Argumentchanging properties of classifiers in ASL." Natural Language \& Linguistic Theory 22 (4): 743-810.

Cecchetto, Carlo, Carlo Geraci, and Sandro Zucchi. 2006. "Strategies of relativization in Italian sign language.” Natural Language \& Linguistic Theory 24 (4): 945-975.

2009. "Another way to mark syntactic dependencies: The case for right-peripheral specifiers in sign languages.” Language, 278-320.

Comrie, Bernard. 1976. "The syntax of causative constructions: cross-language similarities and divergences." In The grammar of causative constructions, edited by Masayoshi Shibatani, 259-312. New York: Academic Press.

Folli, Raffaella, and Heidi Harley. 2007. "Causation, obligation, and argument structure: On the nature of little v.” Linguistic Inquiry 38 (2): 197-238.

Geraci, Carlo, and Valentina Aristodemo. 2016. "An in-depth tour into sentential complementation in Italian Sign Language:" in A Matter of Complexity: Subordination in Sign Languages, edited by Roland Pfau, Markus Steinbach, and Annika Herrmann, 95-150. Berlin: De Gruyter Mouton. https://doi.org/doi:10.1515/9781501503238-006. 
Geraci, Carlo, Carlo Cecchetto, and Sandro Zucchi. 2008. "Sentential Complementation in Italian Sign Language." WECOL 2008, 46.

Gutman, Ariel. 2010. "Expressing causative situations in French Sign Language (LSF).” https: / / www.academia.edu / 12646699 / Expressing_causative_situations_in_French_Sign_ Language_LSF_.

Harley, Heidi. 1995. "Subjects, events, and licensing." PhD diss., Massachusetts Institute of Technology.

. 2008. "On the causative construction." In Handbook of Japanese Linguistics, edited by Shigeru Miyagawa, 20-53. Oxford: OUP.

Kayabaşı, Demet, and Kadir Gökgöz. 2020. "The Causative-Inchoative Alternation in TİD and the Age of Acquisition Effects on Complex Clauses." Paper presented at FEAST 2020.

Kimmelman, Vadim. 2018. "Basic argument structure in Russian Sign Language.” Glossa: $a$ journal of general linguistics 3 (1): 116. https://doi.org/https://doi.org/10.5334/gjgl.494.

Kulikov, Leonid I. 2001. "Causatives.” In Language typology and language universals. An international handbook. Vol. 2, edited by Martin Haspelmath, E König, W Oesterreicher, and W Raible, 886-898. Walter de Gruyter.

Loos, Cornelia, et al. 2017. "The syntax and semantics of resultative constructions in Deutsche Gebärdensprache (DGS) and American Sign Language (ASL).” PhD diss., University of Texas, Austin.

Martin, Fabienne, and Florian Schäfer. 2014. "Causation at the syntax-semantics interface." In Causation in grammatical structures, edited by Bridget Copley and Fabienne Martin, 209-244. Oxford University Press Online.

Pylkkänen, Liina. 2002. “Introducing arguments.” PhD diss., MIT.

2008. Introducing arguments. Cambridge: MIT press.

Tang, Gladys, and Gu Yang. 2007. "Events of motion and causation in Hong Kong Sign Language.” Lingua 117 (7): 1216-1257.

Tubino Blanco, Mercedes. 2010. "Contrasting causatives: A minimalist approach.” PhD diss., The University of Arizona, Tucson. 